\title{
MINIMALIST THEORY OF FICTION AND THE ICTHINKING® METHOD AS A BACKGROUND FOR NEW INSIGHTS TO AUTISM
}

\author{
Crister Nyberg'i, \\ Amanda Ptolomey ${ }^{2}$ \\ 1 University of Jyväskylä, \\ Department of Social Sciences and Philosophy, \\ Finland \\ 2University of Glasgow, \\ Strathclyde Centre for Disability Research, \\ School of Social and Political Sciences, \\ United Kingdom
}

\begin{abstract}
:
The standard approach to conceptual understanding in the case of autism uses the distinction of abstract versus concrete thinking. This approach has its benefits but fails to explain all features of language use. For example, some concepts change their meaning in different contexts in contrast to concepts that are more rigid in their uses, such as mathematical concepts. This idea has its background in Minimalist theory of fiction (MTF), a theory that considers 'skills to use words' essential for understanding fiction, contrasting with theories that require pretending or make believe to understand fiction. From this background, the theory of Integrative Complexity (IC), and the method animating for practice, ICthinking ${ }^{\circledR}$, can be of particular use to autistic people. The interventions develop meta-cognitive skills and are supportive of autistic people. From these starting points, we introduce new research hypotheses for developing educational methods especially for autistic people.
\end{abstract}

Keywords: autism, integrative complexity, metacognition, fiction

\section{Changing contexts}

Fictional characters raise philosophical problems because of their ontological status. If we follow the traditional theories of meaning and reference, names like 'Sherlock Holmes' are problematic: is Sherlock Holmes real or imaginary or both? Similarly, stories involving our heroes like Luke Skywalker or Lara Croft are a challenge for philosophers who insist on there being some referent in real life in order to make statements with truth value, that is, evaluated as 'true' or 'false'. What makes the situation even more

i Correspondence: email crister.nyberg@haaga-helia.fi 
complicated is that these stories include statements that are actually true in real life (a particular poison does kill in a particular way). Approaches to these problems range from more straightforward traditional answers offered in classic texts by Gottlob Frege (1892) and Bertrand Russell (1905) to complicated systems of existence like Alexius Meinong's (1905) account and its further developments in Edward Zalta's (1983) and Terence Parson's (1980, 2000) theory on abstract objects. There is an obvious need for making a difference between fictional and real-life objects. The answers following Meinong try to save the idea of referent by considering different levels of existence. Another recent and widely accepted way to deal with fiction is to apply the concept of make believe or pretense $^{\text {ii }}$ (e.g. Walton 1990, Currie 1990 and Evans 1982). In the case of fictional or abstract objects, we are invited to make believe (or pretend) their existence.

All these approaches have their pros and cons but a new alternative with useful applications to different fields is offered by the Minimalist Theory of Fiction (MTF) (Nyberg 2015, 2016, 2018). MTF takes its point of view from use theory of meaning and minimal theory of truth ${ }^{\text {iii. }}$. It stresses the recognition of different uses of words i.e. language games. Fiction, all abstract objects, scientific use of language, everyday uses of language are all the same in that each context has its own rules for the right uses of words. If we change the focus from ontological matters (is this true or false) to a contextappropriate use of words we can concentrate on developing skills like reading social and contextual cues and metacognition. Attention can then be paid to metarepresentation and metacognitive skills: to develop metacognitive skills it is essential to use educational practices that require metarepresentation, the second-order presentation of first order cognitive contents ${ }^{\text {iv }}$ (a drawing is a representation of something and someone looking at the drawing represents it in their mind).

Pretence is apparently involved when we are participating in, for example, a play where we are exaggerating our feelings in order to convincingly perform the characters. However, for our performance to be convincing we must understand what is going on in that particular context, the play. Thus, understanding precedes pretending. On the other hand, there are games or language games where we adjust our behavior to the context without necessarily knowingly doing so (without understanding). In general, pretense is defined as acting in a way that is contrary to how the world is. Pretending by its definition (e.g. Garvey 1990) requires acting symbolically, or non-literally, in a way that is contrary to reality. In developmental psychology, a challenging question is when exactly do children actually start pretending? Pretense seems to emerge during the second year of life and it is considered puzzling that it emerges so early, at the same time as children are constructing their own concepts of the world and reality (Randell \& Nielsen 2007).

\footnotetext{
ii Pretence theories about fiction claim we are merely pretending the truth of the sentences or the existence of the objects involved in fiction. Kendall Walton's theory is allegedly the most influential one of the pretense theories. In his theory representational works function as props in games of make believe just like dolls and toy trucks serve as props in children's games. (Walton 1990).

iii See Horwich 1998a, 1998b and Wittgenstein 1999.

iv E.g. Proust 2007.
} 
Accordingly, pretense is understood to play a significant role in children's social cognitive development. In practice, this means, for example, playing games where objects can stand in for other unrelated objects thus requiring a lot of imagination (a broom becomes a horse, or a cardboard box a ship to outer space) Randell and Nielsen (2007, 128) Leslie (1987). There is no reason to question these important stages of psychological development but what is disputable is the nature of pretend play. Pretend play is seen as a developmental landmark in the child's acquisition of a 'Theory of Mind" (Leslie, 1987). There is a wide discussion questioning Leslie's (1987) view on pretend play and in general the result of this discussion is that there are different types and levels of pretend play, and that all pretense is not metarepresentational (e.g. Gordon 1986, 1992, Goldman 1989, Nyberg 2015, 2016). Looking at these processes from the perspective of the language user, we do not take a stance on questions concerning theory of mind but ask instead what kind of skills are required when pretense is going on. For the purposes of this discussion, it is important to note that autistic children usually show low levels of pretend play ${ }^{\mathrm{vi}}$. In the remaining sections, we will begin to explore using the theory Integrative Complexity (IC) and its further development by IC Thinking researchers to discover new methods for improving the language skills of autistic children.

\section{Integrative complexity}

Integrative complexity is simultaneously a concept and a measure based on over forty years of research. Pioneered by Suedfeld and Tetlock ${ }^{\text {vii }}$ the integrative complexity (IC) measurement frame analyses the level of cognitive complexity in a spoken or written statement, emphasizing structure over content. As a concept, IC refers to the cognitive lens through which human beings view the social world during real or perceived conflict. When faced with disagreement or difference relating to issues core to our values and identity, the social world can be perceived through a narrow, restricted lens resulting in black and white thinking (Low IC). In contrast, it is possible to engage with the social world - even when faced with threat or disagreement - with a more deliberate, flexible thinking style while remaining connected to our most important values and identity. This expansive thinking style supports peaceful solutions (High IC). The IC Thinking Research Group operationalized the concept of IC by designing a range of interventions that increase IC flexibility.

\footnotetext{
"By 'Theory of Mind' is referred to the "ability to reason and make inferences about another's mental states, and presupposes the ability to hold beliefs about another's beliefs, or to mentally represent another's mental representation".

vi E.g. Chris Jarrold \& al. 1994.

vii See e.g. (Suedfeld \& Rank 1976, Suedfeld \& Tetlock 1977, Suedfeld, Tetlock \& Ramirez 1977, Suedfeld, Tetlock \& Streufert 1992).
} 


\section{Finding rules and playing games}

Adapting an approach that focuses on the language user, we will view pretense as a metarepresentational position ${ }^{\text {viii }}$. However, we can dispense with the concepts of pretense or make believe because they are mainly about acting against our beliefs. Rather than interpreting early signs of pretense in children's development as knowingly acting in a way contrary to reality, we will focus on their ability to play the language game in question, or put another way, their skills to use language. For our argument, what is essential in pretense is the ability to use words differently in different contexts. We can understand a fictional story without knowingly viewing its statements as contrary to reality, although we have a better understanding of the story if we do recognize its relationship to other language games, for example, to those about reality. The better understanding of the different uses of the words the more interpretations are available (Nyberg 2015, 2016, 2018). In our view, this is undoubtedly linked to metarepresentational abilities and metacognition. Recognizing and comparing different language games or interpretations of a story requires metarepresentation and metacognitive abilities.

It is a familiar claim that autistic children lack a "theory of mind" because of an inability to metarepresent. In this claim, the skills to use language are determinative and the failure to recognize different uses of the same word in the same event is interpreted as an inability to metarepresent or imagine. While metarepresentation and imagination may be involved, focusing instead on the use of language (rather than theory of mind) may yield new insights for educational practices that will improve language skills and metacognitive abilities. Traditional approaches to investigating the thinking of autistic children do not take into account a language user's position. In test situations participants are asked to interpret the meanings of words used in an experimental scenario. Taking into account an autistic participant's point of view will offer new insights. For example, the well-known Sally-Anne test represents an experimental scenario that be looked at as a collection of multiple language games in which recognizing right uses of words is essential.

As a traditional test to investigate "theory of mind" in autistic children, the SallyAnne Test is used in developmental psychology to measure a person's social cognitive ability to attribute false beliefs to others. It has been used to identify how some autistic

\footnotetext{
viii This is a problematic position since it is disputable whether early signs of pretense play is metarepresentational. In Nyberg 2016 it is argued that it is possible to fulfil the characteristics of pretense play without being aware of it. This is possible in the light of MTF. Thus, the claim that pretense play is metarepresentational means here that one states knowingly false claims and in addition adjusts feelings to this context.
} 
children $^{\text {ix }}$ have difficulty understanding other people's perspectives and was famously implemented by Simon Baron-Cohen, Alan M. Leslie, and Uta Frith (1985) ${ }^{x}$.

In the Sally-Anne experiment as described by Baron-Cohen et al. (1985) two dolls were presented to children Sally and Anne: "First, we checked that the children knew which doll was which (Naming Question). Sally first placed a marble into her basket. Then she left the scene, and the marble was transferred by Anne and hidden in her box. Then, when Sally returned, the experimenter asked the critical Belief Question: "Where will Sally look for her marble?". If the children point to the previous location of the marble, then they pass the Belief Question by appreciating the doll's now false belief. If however, they point to the marble's current location, then they fail the question by not taking into account the doll's belief. These conclusions are warranted if two control questions are answered correctly: "Where is the marble really?" (Reality Question); "Where was the marble in the beginning? (Memory Question)."

If we compare this situation (the scene with Sally hiding the marble etc.) to a particular ICthinking ${ }^{\circledR}$ session where participants take different positions in written statements and subsequently IC coders evaluate what has been written in order to assign an IC score, then we can see crucial resemblances. Looking at things from different perspectives represents an understanding that words can be used differently, that is, words change their meanings depending on the context and all have less than full understandings of the possible variations in how words may be used. Consider for example the theme of emotions and human relations. A component of ICthinking interventions involves facilitating participants to take on the roles of subjects who hold different perspectives on a make- believe situation, rooted in real-world social issues. This experience requires that participants navigate multiple layers of meaning ${ }^{\mathrm{xi}}$. Participants must understand a) the overall story of the imaginary scenario, b) that they have to play a role, not themselves, c) the character of the role that they are inhabiting in the scenario, d) that others are playing roles also, and e) that there are implicit or explicit connections between the imaginary scenario and 'real world' conflicts. This explicit connection - between the role play and the 'real world' social conflict - is not necessary in order to successfully participate in the game and demonstrates that although role plays rely on the capacity of participants to understand and engage in the use of language games such understanding exists across a spectrum (Nyberg 2018). Crucially, role play also supports embodied cognition - beyond language. In IC Thinking interventions, participants are facilitated to make explicit language-based connections between

\footnotetext{
ix "The Belief Question for both trials was answered consistently by each child with the sole exception of one Down's Syndrome child who failed trial 1 and passed trial 2. The results for Down's Syndrome and normal subjects were strikingly similar. 23 out of 27 normal children, and 12 out of 14 Down's Syndrome children passed the Belief Question on both trials (85\% and $86 \%$ respectively). By contrast, 16 of the 20 autistic children (80\%) failed the Belief Question on both trials. " Simon Baron-Cohen, Alan M. Leslie, and Uta Frith (1985)

${ }^{x}$ Leslie and Frith (1988) found similar results with a similar experiment with human actors (rather than dolls).

xi See Nyberg 2015 and 2018 on intertextuality. General introduction in Still, J. \& Worton M. 1991.
} 
integrative complexity, the role play scenario, their role, and the embodied experience of their thoughts, feelings and emotions (Boyd-MacMillan et al 2016, p.61).

Conceptions of human relations vary greatly between cultures and even families. One goal in IC thinking interventions is to become aware of this. What this means from the perspective of MTF is that in a case of misunderstanding there is a conflict because of different uses of words, i.e., different ideas about words' meanings. The participants are playing different language games. The same phenomenon is present when autistic children $^{\text {xii }}$ fail in the Sally-Anne test. The idea of 'theory of mind' is one way to look at what is happening in the Sally-Anne test, but it can also be thought of as an ability to recognize different language games. It is crucial to recognize different uses of words manifested in the same context. These subgames may be called micro language games belonging to a macro language game ${ }^{\text {xiii }}$. The rules of the games are constructed from social situations where cues are collected from multiple factors. MTF is about right uses of words and it highlights that mastering the use of a word is a skill and thus a matter of a degree. In MTF the concept of truth is essential since it indicates recognition of a metarepresentational position. Taking metarepresentational positions is one important developmental milestone, but equally important are the skills to use words. In the case of autism, it is a familiar phenomenon that children can be rather good in mathematics despite difficulties in other uses of language. In mathematics, the uses of the terms are more rigid than in everyday use of language. Their meanings do not change when the context changes. In everyday uses of language, the meanings are often constructed in situations where a great amount of contextual information is needed in order to follow the rules of the language game that determines the right meanings of those words in that context, i.e., how the words are being used. If this line of reasoning is correct, then it implies that understanding mathematics does not essentially require either pretending or meta-representational capacity or following context specific, meaning constituting, rules.

It seems that the way autistic children use all kinds of concepts is similar to the way they use mathematical concepts. This suggests that the process where the use of a concept is learnt is particularly crucial in the case of autism since it is connected to a rigid use of words. This causes problems not only because meanings vary in different contexts but also because there can be many contexts, that is many language games present in one conversation. If one way of using a word is determinative, then it prevents recognizing alternative, legitimate uses, i.e., other perspectives. While 'theory of mind' is one way to understand what is happening, it does not explain or describe the great differences that can exist among children in their grasp of the meanings of words, what we have been referring to as skills to use words. One may of course argue whether theory of mind or skills to use words is the determinative factor, but our argument is that exploring the role

\footnotetext{
xii 'autistic people have been shown to prefer 'identity-first' language' see Dunn and Andrews 2015; Kenney et al 2016; Botha et al, 2021'

xiii For example a discussion can be about Christianity (macro language game) with different language games going on depending on the orientation (micro language game).
} 
of language skills and the process whereby the uses of words are learnt may lead to new educational practices that increase skills for managing in different situations.

The right use of the word marble in Sally-Anne test is dependent on which language game is in question. The description of the test uses three different names of the contexts; the 'belief' question, the 'reality' question and the 'memory' question. What this requires from the language user is the recognition that the rules are different in those games. This learning is facilitated in IC Thinking interventions. Recognizing that different language users are using words differently is a key to differentiation, the first step in IC flexibility.

\section{Future research}

Areas for future research include firstly the development or enhancement of interventions to increase IC flexibility which place even greater emphasis on participatory methods. These methods should provide mechanisms for learning that rely less on the use of language games (involved in both verbally and socially-cued non-verbal communication). This could include the development and use of participatory visual methods which have been suggested as efficacious in supporting researchers to access insights 'which would be difficult to perceive and understand through words (and numbers) alone' (Hickmann, 2007, p.322. See also Bagnoli, 2009, Mannay, Staples and Edwards, 2017).

Secondly, we suggest that adaptations to the IC coding manual are required to be inclusive of autistic people. This would involve a) a process through which to baseline the language capabilities of participants before administration of the IC measurement framework and b) in line with our suggestions above, adaptations to the current coding regime which are capacious enough to incorporate participatory visual and movementbased demonstrations of integrative complexity which do not rely on usage of language games.

Finally, we suggest that the differences in language use we have explored here may be evidenced empirically using the existing, unmodified IC coding manual. Specifically, we suggest further investigation may suggest that autistic people exhibit a particular IC profile. We hypothesise that autistic people may exhibit higher levels of elaborative complexity (complexly elaborated viewpoint on one perspective) than dialectical complexity (presence of a tension between more than one perspective) (Conway et al, 2008).

\section{Acknowledgement}

Special thanks to Dr. Eolene Boyd-MacMillan for valuable feedback.

\section{Conflict of Interest Statement}

The authors declare no conflicts of interests. 


\begin{abstract}
About the Authors
Crister Nyberg (PhD) is a Visiting Researcher in University of Jyväskylä, Department of Social Sciences and Philosophy. Principal Lecturer in Haaga-Helia University of Applied Sciences, School of Vocational Teacher Education.
\end{abstract}

Amanda Ptolomey is a Doctoral Researcher of University of Glasgow, Strathclyde Centre for Disability Research, School of Social and Political Sciences.

\title{
References
}

Bagnoli, A. (2009). Beyond the standard interview: The use of graphic elicitation and artsbased methods. Qualitative research, 9(5), pp.547-570.

Bakhtin, M. M. (1981). The Dialogic Imagination: Four Essays. Ed. Michael Holquist. Trans. Caryl Emerson and Michael Holquist. Austin and London: University of Texas Press.

Baron-Cohen, S., Leslie, A. M., \& Frith, U. (1985). Does the autistic child have a 'theory of mind'? Cognition, 21, 37-46

Berk, L. E. (2003). Child development. Boston, MA: Allyn and Bacon.

Botha, M., Hanlon, J. and Williams, G.L., 2021. Does language matter? Identity-first versus person-first language use in autism research: A response to Vivanti. Journal of Autism and Developmental Disorders, pp.1-9.

Boyd-MacMillan, E. (2016). Increasing Cognitive Complexity and Collaboration Across Communities: Being Muslim Being Scottish. Journal of Strategic Security (Vol. 9). https://doi.org/10.5038/1944-0472.9.4.1563

Boyd-MacMillan, E., Fearon, P., Ptolomey, A., \& Mathieson, L. (2016). I SEE! Scotland: Tackling Sectarianism and Promoting Community Psychosocial Health. Journal of Strategic Security, 9(4), 53-78. https://doi.org/10.5038/1944-0472.9.4.1556

Brown, A. L. (1987). Metacognition, executive control, self-regulation, and other more mysterious mechanisms. In F. E. Weinert \& R. H. Kluwe (Eds.), Metacognition, motivation, and understanding (pp. 65-116). Hillsdale, New Jersey: Lawrence Erlbaum Associates.

Conway III, L. G., Thoemmes, F., Allison, A. M., Towgood, K. H., Wagner, M. J., Davey, K., Salcido, A., Stovall, A. N., Dodds, D. P., Bongard, K. and Conway, K. R. (2008). Two ways to be complex and why they matter: Implications for attitude strength and lying. Journal of Personality and Social Psychology, 95(5), p.1029.

Currie, G. (1990). The Nature of Fiction. Cambridge: Cambridge University Press.

Dunn, D. S., \& Andrews, E. E. (2015). Person-first and identity-first language: Developing psychologists' cultural competence using disability language. American Psychologist, 70(3), 255-264.

Evans, G. (1982). The Varietes of Reference. New York: Oxford University Press Field

Flavell, J. (1976). Metacognitive aspects of problem-solving. In L. Resnick (Ed.), The Nature of Intelligence. Hillsdale, NJ: Erlbaum Assoc. 
Frege, G. (1892). 'Über Sinn und Bedeutung', in Zeitschrift für Philosophie und philosophische Kritik, 100: 25-50. Translated as 'On Sense and Reference' by M. Black in Translations from the Philosophical Writings of Gottlob Frege, P. Geach and M. Black (eds. and trans.), Oxford: Blackwell, third edition, 1980.

Garvey, C. (1990). Play (2nd ed.). Cambridge, MA: Harvard University Press

Goldman, A. I. (1989). Interpretation psychologized. Mind and Language, 4, 161-185.

Gordon, R. M. (1986). Folk psychology as simulation. Mind and Language, 1, 158-171.

Gordon, R. M. (1992). The simulation theory: Objections and misconceptions. Mind and Language, 7, 11-34.

Happé, F. (1995). Understanding Minds and Metaphors: Insights from the Study of Figurative Language in Autism. Metaphor and Symbolic Activity, 10:4, 275-295

Hickman, R. (2007). Visual art as a vehicle for educational research. International Journal of Art \& Design Education, 26(3), pp.314-324.

Horwich, P. 1998. Truth. Second Edition. Oxford: Clarendon Press.

Horwich, P. 1998b. Meaning. Oxford: Clarendon Press.

Jarrold, C., Carruthers, P., Smith, P. K., \& Boucher, J. (1994). Pretend play: Is it metarepresentational? Mind and Language, 9, 445 - 468

Kenny, L., Hattersley, C., Molins, B., Buckley, C., Povey, C. and Pellicano, E. (2016). Which terms should be used to describe autism? Perspectives from the UK autism community. Autism, 20(4), pp.442-462.

Leslie, A. M. (1987). Pretence and representation: the origins of "theory of mind". Psychological Review, 94, 412-426.

Leslie, A. M., \& Frith, U. (1988). Autistic children's understanding of seeing, knowing and believing. British Journal of Developmental Psychology, 6(4), 315-324.

Lillard, A. S. (1993). Pretend play skills and the child's theory of mind. Child Development, 64, 348-371.

Mannay, D., Staples, E. and Edwards, V. (2017). Visual methodologies, sand and psychoanalysis: employing creative participatory techniques to explore the educational experiences of mature students and children in care. Visual Studies, 32(4), pp.345-358.

Meinong, A. (1905). "Über Gegestandstheorie”, in Untersuchungen zur Gegenstandstheorie und Psychologie, A. Meinong, ed., Leipzig: Barth; English translation, "On the Theory of Objects," in Realism and the Background of Phenomenology, R. Chisholm (ed.), Glencoe: The Free Press, 1960

Morton Ann Gernsbacher \& Sarah R. Pripas-Kapit (2012). Who's Missing the Point? A Commentary on Claims that Autistic Persons Have a Specific Deficit in Figurative Language Comprehension. Metaphor and Symbol, 27:1, 93-105

Nyberg, C. (2015). Fiction in Drama Education Offers Learning Opportunities for All, Philosophical Perspectives in Drama Education. The European Journal of Social and Behavioural Sciences. EJSBS Volume XII (eISSN: 2301-2218) 
Nyberg, C. (2016). Fiction, Truth and Reference. Minimalist Theory of Fiction. In P. Stalmaszczyk (Ed), From Philosophy of Fiction to Cognitive Poetics. Studies in Philosophy of Language and Linguistics, Volume 4. Peter Lang Edition.

Nyberg, C. (2018). Truth in Fiction Reconsidered. In S. H. Klausen (Ed), Res Cogitans. Vol 13, No 1. Frontiers in the philosophy of literature.

Nyberg, C. (2018). Philosophical Background of Integrative Complexity. To be submitted. Parsons T. (1980). Nonexistent objects. New Haven/London: Yale University Press 1980.

Parsons T. (2000). Indeterminate Identity: metaphysics and semantics. Oxford: Oxford University Press.

Randell, A \& Nielsen, M. (2007). Children's Communication of Pretend Acts Using Social Cues, In M. A. Vanchevsky (Ed), Frontiers in Cognitive Psychology, Nova Science Publishers

Russell, B., (1905). ‘On Denoting', Mind 14 (October): 479-493

Still, J. \& Worton M. (1991). "Introduction." Intertextuality: Theories and Practices. Ed. Judith Still and Michael Worton. Manchester: Manchester University Press, 1991.

Suedfeld, P., \& Rank, A. D. (1976). Revolutionary leaders: Long-term success as a function of changes in conceptual complexity. Journal of Personality and Social Psychology, 34, 169-178.

Suedfeld, P., \& Tetlock, P. (1977). Integrative complexity of communications in international crises. Journal of Conflict Resolution, 21, 169-184.

Suedfeld, P., Tetlock, P. E., \& Ramirez, C. (1977). War, peace, and integrative complexity. Journal of Conflict Resolution, 21, 427-442.

Suedfeld, P., Tetlock, P. E., \& Streufert, S. (1992). Conceptual/integrative complexity. In C. P. Smith, J. W. Atkinson, D. C. McClelland, \& J. Veroff (Eds.), Motivation and personality: Handbook of thematic content analysis (pp. 393-400). New York: Cambridge University Press.

Taylor \& Francis Baron-Cohen, S., Leslie, A. M., \& Frith, U. (1985). Does the autistic child have a 'theory of mind'? Cognition, 21, 37 \pm 46 .

Walton, K. (1990). Mimesis as Make-Believe. Cambridge, Harvard University Press

Wittgenstein, L. (1999). [1963] Filosofisia tutkimuksia. Transl. By Heikki Nyman. Porvoo: WSOY. (originally Philosophische Untersuchungen 1953)

Zalta, E., (1983). Abstract Objects: An Introduction to Axiomatic Metaphysics, Dordrecht: D. Reidel. 
Creative Commons licensing terms

Authors will retain the copyright of their published articles agreeing that a Creative Commons Attribution 4.0 International License (CC BY 4.0 ) terms will be applied to their work. Under the terms of this license, no permission is required from the author(s) or publisher for members of the community to copy, distribute, transmit or adapt the article content, providing a proper, prominent and unambiguous attribution to the authors in a manner that makes clear that the materials are being reused under permission of a Creative Commons License. Views, opinions and conclusions expressed in this research article are views, opinions and conclusions of the author(s). Open Access Publishing Group and European Journal of Special Education Research shall not be responsible or answerable for any loss, damage or liability caused in relation to/arising out of conflict of interests, copyright violations and inappropriate or inaccurate use of any kind content related or integrated on the research work. All the published works are meeting the Open Access Publishing requirements and can be freely accessed, shared, modified, distributed and used in educational, commercial and non-commercial purposes under a Creative Commons Attribution 4.0 International License (CC BY 4.0). 